International Journal of Poultry Science 14 (9): 521-528, 2015

ISSN 1682-8356

(C) Asian Network for Scientific Information, 2015

\title{
Ho Chicken in Bac Ninh Province (Vietnam): From an Indigenous Chicken to Local Poultry Breed
}

\author{
Nguyen Van Duy,, Nassim Moula², Do Duc Luc ${ }^{1,3}$, Pham Kim Dang ${ }^{3}$, \\ Dao Thi Hiep ${ }^{3}$, Bui Huu Doan ${ }^{3}$, Vu Dinh Ton ${ }^{3}$ and Frederic Farnir ${ }^{2}$ \\ ${ }^{1}$ Centre for Interdisciplinary Research on Rural Development, \\ Vietnam National University of Agriculture, Vietnam \\ ${ }^{2}$ Department of Animal Production, Faculty of Veterinary Medicine, University of Liege, Liege 4000, Belgium \\ ${ }^{3}$ Faculty of Animal Science, Vietnam National University of Agriculture, Vietnam
}

\begin{abstract}
The objectives of this study were to determine the morpho-biometric characteristics of Vietnamese indigenous Ho chicken breed and to evaluate its production, reproduction performance and egg quality. The study was carried out on 20 households raising purebred Ho chicken from September 2013 to April 2015 in Northern Vietnam. Morpho-biometric characterization was based on measurement of 128 adult individuals. The egg production was observed on 66 hens within 20 households. A total of 29 eggs were freshly collected from 8 hens at the 20th laying week for quality analysis. Ho chicken breed is a breed with a large dimension, a large diversity in the colors (black with gold hackle, black copper, wheat, tan and tricolor), a heavy weight (3.78 and 2.64 for adult males and females, respectively), a low egg production (12.73 eggs/clutch) and a relatively low rate of embryo eggs $(72.81 \%)$. A research to improve the egg production and reproduction should be undertaken to obtain a better performance, economic efficiency while maintaining this genetic heritage and sustaining the biodiversity of the avian breeds in Vietnam.
\end{abstract}

Key words: Vietnam, indigenous chicken, biodiversity, productivity, egg quality

\section{INTRODUCTION}

Livestock production is an important and promising agricultural sector in the context of an increasing world demand for animal products and their high added value (Delgado et al., 1999). In a global environment with economic and ecological challenges for sustainable development, farming practices have been facing profound changes. In this context, the protection of biodiversity becomes a vital need, given the numerous pressures and threats it faces. The poultry production is no exception to the general phenomenon of genetic erosion (Besbes, 2009). A rapid spread of intensive farming practices with hybrid breeds has been led to the detriment of local chicken breeds, while these continue playing a central role in rural socio-economic development in various regions of the world.

In Vietnam, poultry farming is very important. According to the General Statistics Office of Vietnam (GSO), in 2013 , the slaughtered poultry meat production in whole country accounted for 774.7 thousand tons and was ranked second after the pork production (GSO, 2014). Local breeds make up the largest part of the poultry population, the industrial lines only accounting for a small percentage. In 2003 , in Vietnam, only $20 \%$ of the poultry herd originated from industrial chickens, mainly obtained by crossbreeding over a total number of 166.6 million chickens (Vang et al., 1999; Eaton et al., 2006).
More recently, indigenous chicken breeds in Vietnam have been estimated to amount to $85 \%$ of the total chicken flock (Phan Dang et al., 2009). According to Moula et al. (2012a,b), the local chicken breeds in Vietnam include Ri, Te (or Lun, short leg), Tau Vang, Ac (black meat, white or black feather), Oke, H'mong, Tre, Choi (fighting chicken), PhuLuuTe, To, Dan Khao (six toes), Mia, Ho, Dong Tao (thick legs) and Van Phu. With a reproductive flock of 86.63 to 93.30 million individuals, the Ri breed was also commonly called "Ga Ta" (native chicken) accounting for 52 to $56 \%$ of total local chicken herd (Eaton et al., 2006). Under the pressure of the rapid development of poultry production worldwide (Besbes, 2009), many local chicken breeds have been threatened with extinction. In Vietnam, the Mia, Ho and Dong Tao chicken breeds have been reported as endangered or critical breeds, while the Van Phu chicken breed has been lost during the last years (Tieu, 2009). However, in the developing countries like Vietnam, the local chicken breeds still play as an important tool for the rural development and poverty fighting. Moreover, any loss of biodiversity would potentially threaten these countries ability to meet the future ecological and economic challenges. In this context and as a first step towards Vietnamese local breed conservation, this study aims to determine the morpho-biometric characteristics of the Ho chicken breed and to evaluate its growth and 
reproductive performance including laying rate and egg quality. This study plays as the foundation for a rehabilitation of Vietnamese local chicken breeds, which is especially suitable with less intensive farming conditions and that plays a paramount role on socioeconomic and cultural aspects.

\section{MATERIALS AND METHODS}

This study was carried out on 20 households raising purebred Ho chicken from September 2013 to April 2015 in Ho town (located $30 \mathrm{~km}$ north of Hanoi), Thuan Thanh district, Bac Ninh province in Northern Vietnam.

Morpho-biometric characterization: Morpho-biometric characterization was based on measurement of 128 adult individuals (27 males and 101 females over six months of age). The body sizes were measured according to FAO standards (FAO, 2012). A mechanical scale (accuracy $\pm 10 \mathrm{~g}$ ) was used to weigh the chicken while a tape measure and an electronic sliding caliper (accuracy $\pm 0.01 \mathrm{~mm}$ ) and a tape measure were used for measuring the body sizes. The collected traits were body weight and the body sizes (body length, beak length, comb length, comb height, wattles length, wattles height, neck length, back length, wing length, thoracic perimeter, thigh length, tarsus length and tarsus diameter) together with information about the feather color, tarsus color, beak color, feathers color and comb type.

Egg production performance: The egg production was observed on 66 hens of different ages within 20 households. The hens were raised in traditional conditions inside simple houses to avoid the sun light and rain and had a small playground for the chickens. The animals were fed by a mixed ration including paddy $(20.45 \%)$, rice $(27.97 \%)$, rice bran $(10.88 \%)$, maize $(8.39 \%)$, aquatic vegetable $(30.36 \%)$ and industrial feed (1.95\%). The nutrition components for this mixed ration were $5.3 \%$ crude protein, $2.47 \%$ ash, $0.26 \%$ calcium, $0.36 \%$ phosphorus and $2483 \mathrm{kcal} \mathrm{ME} / \mathrm{kg}$. The eggs were collected daily and the incubation was made by hens or turkeys. The production traits were number of eggs per clutch, number of clutch per year, number of eggs/hen/year, number of embryonated eggs per clutch, rate of embryonated egg per clutch, number of chicks per clutch, rate of chicks born per clutch, number of chicks born alive per clutch, survival rate of chicks per clutch and number of chicks per year.

Egg quality: A total of 29 eggs were freshly collected from 8 hens at the 20th laying week for quality analysis. Twenty three eggs were used for quantitative traits and chemical composition analysis of eggs. The six others were sent to the National Institute for Food Control, Vietnam for determining amino acid, cholesterol and omega contents. The quantitative traits were assessed through measurements of egg weight, yolk weight, shell weight, albumen weight, yolk diameter, albumen height, Haugh unit, maximum breakage force, yolk color, egg length, egg width and shape index. Egg chemical compositions were dry matter, ash, crude protein and lipids while amino acids were aspartic acid, serine, glutamic acid, glycine, histidine, arginine, threomine, alanine, proline, cysteine, tyrosine, valine as well as cholesterol and omega 3.

The eggs were weighed using an electronic scale (accuracy $0.01 \mathrm{~g}$ ). Lengths and widths were measured using an electronic sliding caliper (accuracy $0.01 \mathrm{~mm}$ ). Egg shape index was calculated by ratio between length and width. Eggs were broken with careful separation of yolk and albumen. The shell and yolk were weighed separately. Albumen weight was determined by subtracting the yolk and shell weights from the total egg weight. Yolk and albumen was used for chemical composition analysis. Chemical compositions were determined according to standard AOAC methods (AOAC, 1990) in the laboratories of the Faculty of Animal Science, Vietnam National University of Agriculture. Amino acid composition was analyzed using HPLC method while omega 3 and cholesterol using GCMS method in National Institute for Food Control, Vietnam.

Statistical analysis: The data were analyzed using the general linear model procedure of SAS software (SAS, 1989) to determine the effect of the sex (male and female) on each morpho-biometric parameter. The descriptive statistics parameters were mean (Mean), standard deviation (SD), minimum (Min), maximum (Max).

\section{RESULTS}

Feather color and aspect: The feather colors and aspects of Ho chickens are presented in the Table 1. Ho chickens are characterized by 5 basic feather colors ( 2 for males and 3 for females). Two main types of feather colors were observed for the males, with the black with gold hackle (Fig. 1a) predominant over the black copper (Fig. 1b). In parallel, for the females, wheat (Fig. 2a) and tan color (Fig. 2b) were the most frequently observed colors, with some hens being tricolor (Fig. 2c). Yellow red toe (Fig. 3a), Yellow (Fig. 3b) and White red toe (Fig. $3 \mathrm{c}$ ) are the three observed types of tarsus color. The first color is the main color for the males while the first and third were typical for the females (Table 1).

Three types of combs were found including Walnut (Fig. 4a), Strawberry (Fig. 4b) and Pea (Fig. 4c). While the dominant type of combs was the walnut $(74.07 \%)$ for the males while, the strawberry $(48.52 \%)$ and the pea $(39.60 \%)$ combs were frequently found in the females (Table 1). 

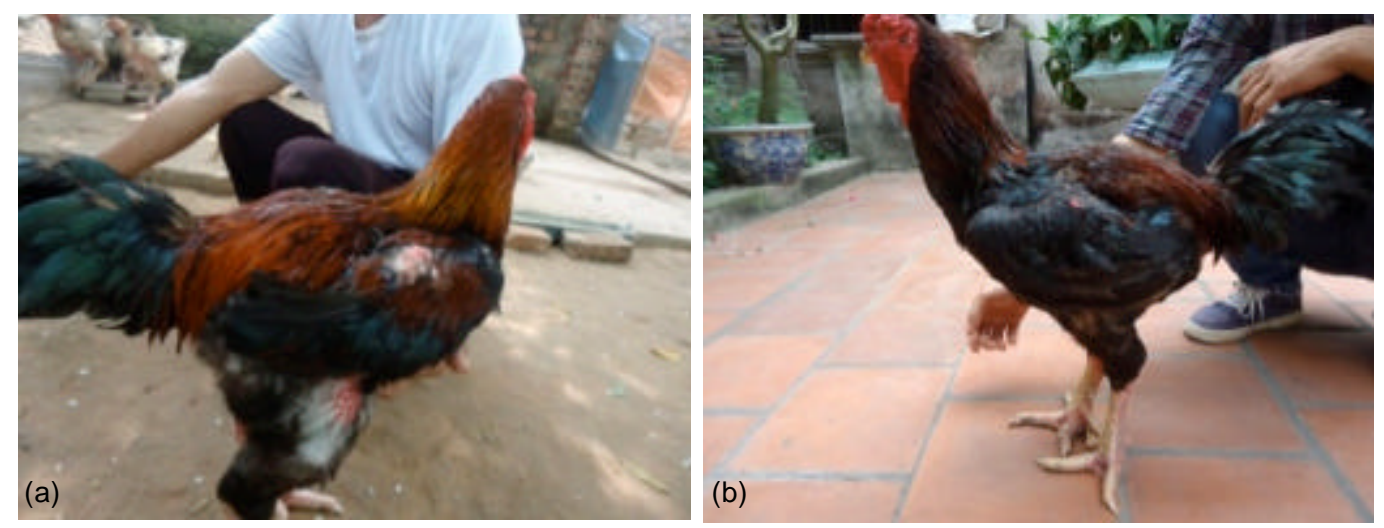

Fig. 1(a-b): (a) Black with gold hackle feather, (b): Black copper feather
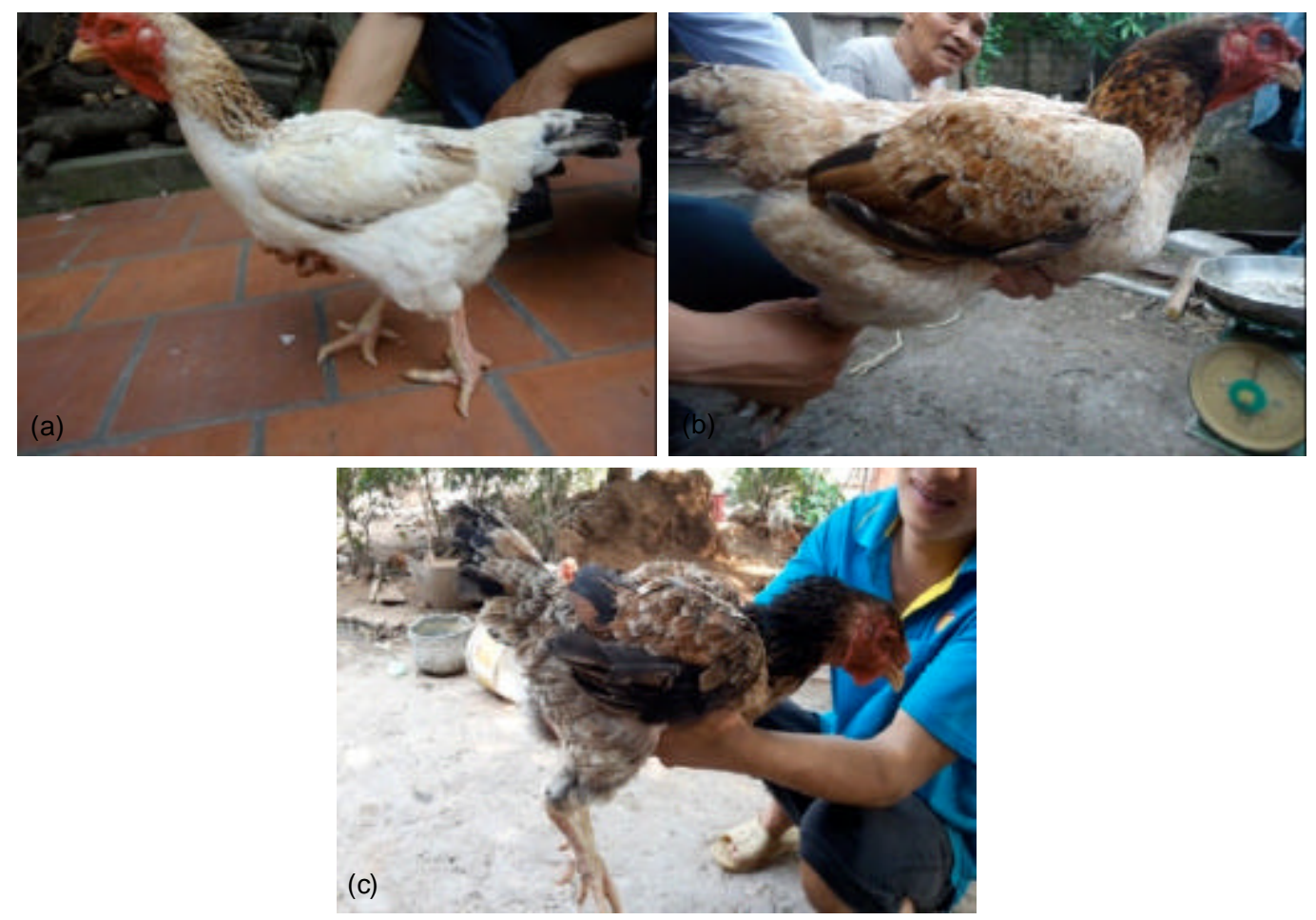

Fig. 2(a-c): (a) Wheat color feather, (b): Tan color feather, (c): Tri color feather

Ho chickens had 2 main beak colors: the dark (Fig. 5a) and the yellow (Fig. 5b). The frequency of occurrence of these colors was also different between males and females. In the males, the two colors occurred with equal frequencies whereas yellow beaks were observed in most females (91.09\%).

Another sexual dimorphism in Ho chickens can be observed through the differences in the feather colors of the ear. Black, Brown, Yellow and White ear feathers were observed, with the black color present only in the males, in which it is largely predominant $(74.07 \%)$ while
Brown (39.80\%) and Yellow (57.14\%) were found recently in the females (Table 1 ).

Morphometric traits: The body weight and body sizes of Ho chickens are shown in the Table 2. These values were significantly different between males and females. The males were heavier than females $(p<0.001)$ and body sizes were larger $(p<0.001)$ for all morphometric parameters. The coefficient of determination $\left(R^{2}\right)$ ranged from 0.7 (for thigh length) to 0.18 (for thoracic perimeter). 

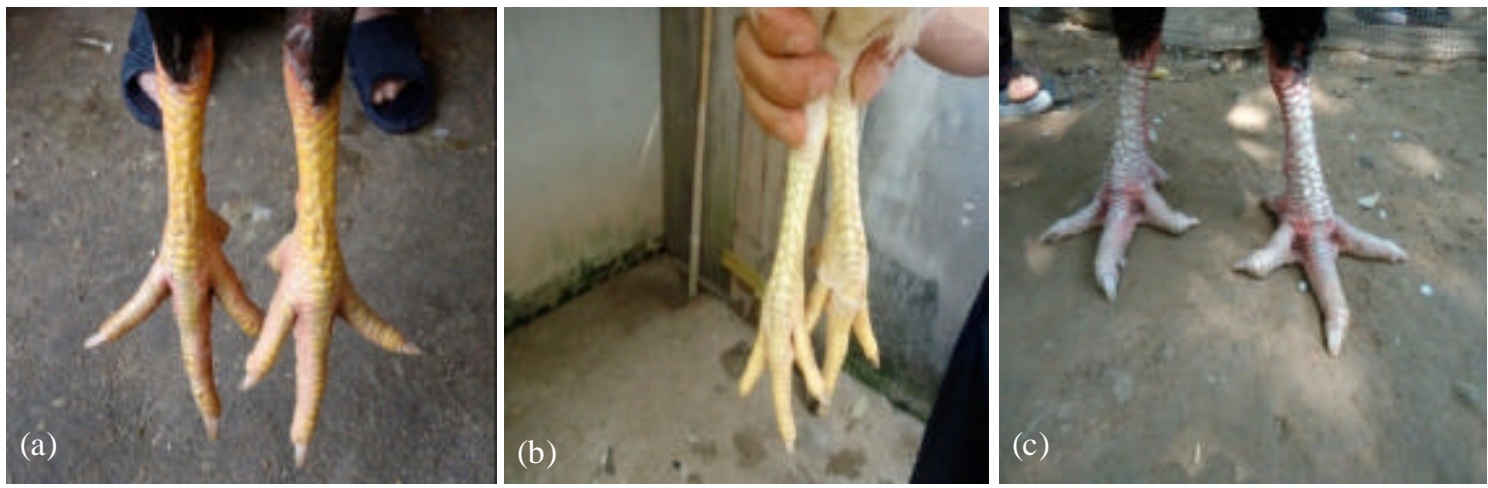

Fig. 3(a-c): (a) Yellow red toe, (b): Yellow toe, (c): White red toe
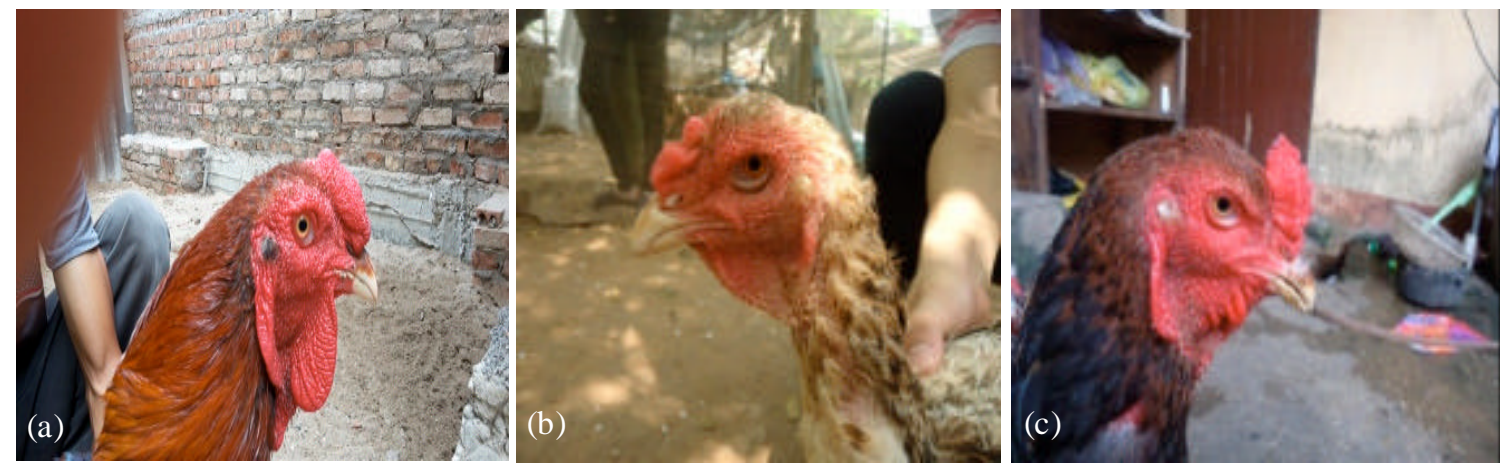

Fig. 4(a-c): (a) Walnut comb, (b): Strawberry comb, (c): Pea comb
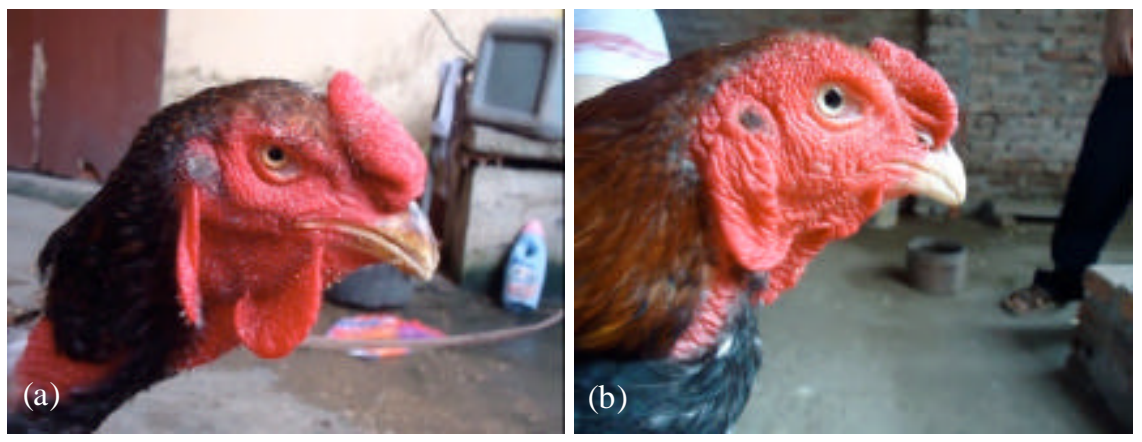

Fig. 5(a-b): (a) Dark beak, (b): Yellow beak

Egg production performance: The results on the reproductive performances of Ho chicken are presented in the Table 3. The egg production of Ho chicken was low (Table 3). The number of eggs per hen per year varied largely between hens (min: 28 and max: 126). This tendency was observed for the other traits. The embryo eggs per clutch (9.25) and the rate of embryo eggs $(72.81 \%)$ were also low for this breed. In average, a hen could give 41.09 chicks during a year.
The quantitative traits and chemical compositions of $\mathrm{Ho}$ chicken eggs are shown in the Table 4. The quantitative egg traits were observed from 23 eggs whereas chemical compositions were from 14 eggs.

The amino acid, cholesterol and omega 3 contents in the yolk and albumen are shown in the Table 6 . Cholesterol and omega 3 in yolk was significantly higher than in the albumen $(p<0.01)$. Among 16 amino acids, the content of 8 acids (aspartic acid, glutamic acid, 
Int. J. Poult. Sci., 14 (9): 521-528, 2015

Table 1: Physical appearance characteristics of Ho chicken

\begin{tabular}{|c|c|c|c|c|c|c|}
\hline \multirow[b]{2}{*}{ Variable } & \multicolumn{2}{|c|}{--------- Male --------- } & \multicolumn{2}{|c|}{-------- Female -------- } & \multicolumn{2}{|c|}{ 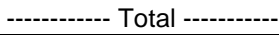 } \\
\hline & $\mathrm{n}$ & $\%$ & $\mathrm{n}$ & $\%$ & $\mathrm{n}$ & $\%$ \\
\hline \multicolumn{7}{|l|}{ Feather color } \\
\hline Black with gold hackle & 20 & 74.07 & - & - & 20 & 15.75 \\
\hline Black copper & 7 & 25.93 & - & - & 7 & 5.51 \\
\hline Wheat & - & - & 55 & 55.00 & 55 & 43.31 \\
\hline Tan & - & - & 34 & 34.00 & 34 & 26.77 \\
\hline Tricolor & - & - & 11 & 11.00 & 11 & 8.66 \\
\hline \multicolumn{7}{|l|}{ Tarsus color } \\
\hline Yellow, red toe & 22 & 84.48 & 48 & 47.52 & 70 & 54.69 \\
\hline Yellow & 1 & 3.70 & 6 & 5.94 & 7 & 5.47 \\
\hline White, red toe & 4 & 14.81 & 47 & 46.54 & 51 & 39.84 \\
\hline \multicolumn{7}{|l|}{ Comb type } \\
\hline Walnut & 20 & 74.07 & 12 & 11.88 & 32 & 25 \\
\hline Strawberry & 5 & 18.52 & 49 & 48.52 & 54 & 42.19 \\
\hline Pea & 2 & 7.41 & 40 & 39.60 & 42 & 32.81 \\
\hline \multicolumn{7}{|l|}{ Beak colour } \\
\hline Dark horn & 14 & 51.85 & 9 & 8.91 & 23 & 17.97 \\
\hline Yellow & 13 & 48.15 & 82 & 91.09 & 105 & 82.03 \\
\hline \multicolumn{7}{|l|}{ Feather color of ear } \\
\hline Black & 20 & 74.07 & 0 & 0.00 & 20 & 16.00 \\
\hline Brown & 4 & 14.82 & 39 & 39.80 & 43 & 34.40 \\
\hline Yellow & 2 & 7.41 & 56 & 57.14 & 58 & 46.40 \\
\hline White & 1 & 3.70 & 3 & 3.06 & 4 & 3.20 \\
\hline
\end{tabular}

Table 2: Morpho-biometric traits of Ho chicken (Mean \pm SD)

\begin{tabular}{|c|c|c|c|c|}
\hline Variable & Males $(n=27)$ & Females $(n=101)$ & $p$-value & $\mathrm{R}^{2}$ \\
\hline Body weigth (kg) & $3.78 \pm 0.04$ & $2.64 \pm 0.07$ & $* * *$ & 0.53 \\
\hline Body length $(\mathrm{cm})$ & $55.25 \pm 0.43$ & $46.84 \pm 0.25$ & *** & 0.64 \\
\hline Beak length (mm) & $42.88 \pm 0.58$ & $37.73 \pm 0.34$ & $* * *$ & 0.26 \\
\hline Back length $(\mathrm{cm})$ & $26.07 \pm 0.35$ & $22.45 \pm 0.20$ & *** & 0.33 \\
\hline Comb length (mm) & $38.65 \pm 0.76$ & $27.86 \pm 0.45$ & $\star * * *$ & 0.51 \\
\hline Comb height (mm) & $18.63 \pm 0.62$ & $8.96 \pm 0.39$ & *** & 0.58 \\
\hline VBreast length $(\mathrm{cm})$ & $21.05 \pm 0.22$ & $17.32 \pm 0.13$ & $* * *$ & 0.57 \\
\hline Neck length $(\mathrm{cm})$ & $22.33 \pm 0.30$ & $19.97 \pm 0.17$ & $* * *$ & 0.21 \\
\hline Tarsus length (cm) & $9.78 \pm 0.13$ & $7.56 \pm 0.07$ & $* * *$ & 0.57 \\
\hline Tarsus diam 1 (mm) & $23.78 \pm 0.24$ & $18.62 \pm 0.14$ & $* * *$ & 0.67 \\
\hline Tarsus diam 2 (mm) & $19.69 \pm 0.29$ & $15.31 \pm 0.17$ & $* * *$ & 0.51 \\
\hline Thigh length $(\mathrm{cm})$ & $19.84 \pm 0.18$ & $16.03 \pm 0.10$ & $* * *$ & 0.70 \\
\hline Thoracic perimeter $(\mathrm{cm})$ & $36.13 \pm 0.40$ & $33.30 \pm 0.24$ & $* * *$ & 0.18 \\
\hline Wattles length $(\mathrm{mm})$ & $31.15 \pm 0.91$ & $22.88 \pm 0.65$ & $* * *$ & 0.32 \\
\hline Wattles height (mm) & $27.05 \pm 1.27$ & $13.89 \pm 0.93$ & $* * *$ & 0.38 \\
\hline Wing length $(\mathrm{cm})$ & $26.94 \pm 0.23$ & $22.72 \pm 0.13$ & $\star * \star *$ & 0.61 \\
\hline
\end{tabular}

Diam 1: Diameter at widest part of tarsus, Diam 2: Diameter at thinnest part of tarsus, ${ }^{* \star *}: p<0.001$

glycine, alanine, tyrosine, valine, leucine and phenylalanine) was not significantly different between albumen and yolk ( $p>0.05)$. Cystine and methionine content in yolk was lower than in albumen $(p<0.05)$.

\section{DISCUSSION}

The morphological characteristics of the Ho chicken show a large feather colors diversity. This result was also found out in the study of Doan and Luu (2006). The diversity of the feather colors of Ho chickens suggests genetic variation in the population of this chicken breed. Through a long historical period, Ho chickens have been raised in the household conditions of the rural area in Vietnam, where many different chicken breeds are grown in the same region. Accordingly, these individuals could go freely from a household to other households without a separating fence, meaning that crosses between the chicken breeds have not been controlled. Nevertheless, some breeding objectives have been pursued. Indeed, this chicken is a traditional product used in important ceremonies associated with spiritual life of Vietnamese people (Moula et al., 2012a,b; Lan Phuong et al., 2015). Cocks with yellow feather colors are normally chosen for the sacrifice (Luan, 2014). As could be expected, this study results have shown that the yellow feather color was dominant in the cock population. This finding is similar to the research results of Doan and Luu (2006) and Thuy (2010). The feather colors in Ho cocks and hens are divided into two obvious separate groups. In detail, the cocks have the dark feather color while the hens have the lighter one. This conclusion was also confirmed by Doan and Luu (2006). 
Int. J. Poult. Sci., 14 (9): 521-528, 2015

Table 3: Reproductive performance of Ho chicken

\begin{tabular}{|c|c|c|c|c|}
\hline Variable & $\mathrm{n}$ & Mean $\pm S D$ & Min & Max \\
\hline Number of eggs per clutch & 66 & $12.73 \pm 2.16$ & 7 & 19 \\
\hline Number of clutch per year & 66 & $5.23 \pm 0.96$ & 4 & 7 \\
\hline Number of eggs/hen/year & 66 & $66.18 \pm 15.14$ & 28 & 126 \\
\hline Number of embryonated eggs per clutch & 65 & $9.25 \pm 2.37$ & 5 & 17 \\
\hline Rate of embryonated egg per clutch (\%) & 65 & $72.81 \pm 11.36$ & 46.15 & 93.75 \\
\hline Number of chicks born per clutch & 64 & $8.03 \pm 2.53$ & 0 & 13 \\
\hline Rate of chicks born per clutch (\%) & 64 & $63.39 \pm 17.05$ & 0 & 92.31 \\
\hline Number of chicks born alive per clutch & 64 & $7.92 \pm 2.60$ & 0 & 13 \\
\hline Survival rate of chicks per clutch (\%) & 64 & $95.68 \pm 17.73$ & 0 & 100 \\
\hline Number of chicks per year & 64 & $41.09 \pm 13.75$ & 0 & 70 \\
\hline
\end{tabular}

Table 4: Quantitative traits and chemical composition of Ho chicken eggs

\begin{tabular}{|c|c|c|c|c|}
\hline Variable & $\mathrm{n}$ & Mean $\pm S D$ & Min & $\operatorname{Max}$ \\
\hline Egg weight (g) & 23 & $52.49 \pm 3.59$ & 44.60 & 59.50 \\
\hline Yolk weight (g) & 23 & $16.59 \pm 1.76$ & 12.40 & 18.70 \\
\hline Egg shell weight $(\mathrm{g})$ & 23 & $5.26 \pm 0.56$ & 3.90 & 6.20 \\
\hline Albumen weight (g) & 23 & $30.51 \pm 2.50$ & 27.10 & 35.10 \\
\hline Yolk diameter (mm) & 23 & $42.85 \pm 1.55$ & 39.61 & 45.10 \\
\hline Albumen height (mm) & 23 & $6.11 \pm 1.14$ & 3.80 & 8.00 \\
\hline Haugh unit & 23 & $79.28 \pm 8.58$ & 58.70 & 92.60 \\
\hline Maximum breakage force $(\mathrm{N})$ & 23 & $34.99 \pm 6.98$ & 15.87 & 47.74 \\
\hline Yolk color (score 1-15) & 23 & $8.09 \pm 2.17$ & 4 & 11 \\
\hline Egg length $(\mathrm{mm})$ & 23 & $53.09 \pm 1.98$ & 48.83 & 56.01 \\
\hline Egg width (mm) & 23 & $41.89 \pm 1.26$ & 40.16 & 44.37 \\
\hline Shape index (\%) & 23 & $79.01 \pm 3.75$ & 73.89 & 87.72 \\
\hline Dry matter (\%) & 14 & $30.15 \pm 2.07$ & 24.04 & 32.47 \\
\hline Ash (\%) & 14 & $1.85 \pm 0.41$ & 1.01 & 2.44 \\
\hline Crude protein (\%) & 14 & $13.03 \pm 0.096$ & 11.49 & 14.28 \\
\hline Lipid (\%) & 14 & $11.44 \pm 2.25$ & 6.82 & 14.00 \\
\hline
\end{tabular}

In the Red River Delta of northern Vietnam, the hens are rarely used in the traditional ceremonies. The hens are mainly raised by the farmers to produce the eggs and chicks. The farmers tend to choose the hens with lighter feather colors because they think these chickens will have a higher reproductive performance. The present research also showed that chickens with the light feather colors were predominant in the hen population. Keambou et al. (2007) noted that the local tropical hens have feathers allowing them to have a better ability to adapt to the weather conditions in their territories.

Leg colors of Ho chickens were rather diverse, with the chickens having yellow shank, red phalanx slots, hock and leg edge being predominant in both cocks and hens populations. In the Ho chicken population, the yellow leg occurred with a low percentage in cocks $(3.70 \%)$ and hens $(5.94 \%)$. According to the elder farmers who have a profound knowledge of Ho chickens, the ancient purebred chickens had yellow legs without mixture with the other colors. However, farmers wanted to improve the legs size to follow the consumer demand. Therefore, Dong Tao chickens (one local chicken breed) were used to cross with Ho chickens in order to produce hybrids with big legs. The current mixed color could relate to the hybridization of Ho chicken population. Additionally, legs play also an important role in the traditional ceremonies such as for national New Year and wedding events (Luan, 2014). Besides that, many Vietnamese people prefer chicken legs as eating hobby. Chicken legs are easily found in the traditional restaurants today.

For the cocks selected for the sacrifice, the comb is an important selection criterion. The local people often choose chickens with bright red combs as the ripe strawberry color and the comb has to be tidy to avoid the situation that the comb be fallen to one side after boiling, because, according to the local people, when the comb is fallen, it means that their business will not be favorable. The comb type of Ho chicken over the years have also been selected according to the farmers orientation, so all three comb types of Ho chickens have tidy shapes, with the walnut comb type accounting for a predominant percentage in the cocks population while the strawberry comb is in the majority in the hens population.

With a long history under the pressures of natural and artificial selection processes, Ho chicken has adapted well to the local conditions in the Red River Delta, Northern Vietnam. The direct observation and description of the phenotype of Ho chicken is an important work to provide information for the research targeting the exploitation of the breed and its sustainable conservation. The phenotypic diversity in the existing $\mathrm{Ho}$ chickens population reveals the introduction of exotic genes resources into the pure Ho chicken population. This is a threat introducing concerns for the genetic resource erosion of the Ho chicken herd. However, 
Int. J. Poult. Sci., 14 (9): 521-528, 2015

Table 5: Amino acid and cholesterol composition in eggs of Ho chicken (Mean \pm SD)

\begin{tabular}{|c|c|c|c|c|}
\hline Variable & Albumen $(n=6)$ & Yolk $(n=6)$ & $\mathrm{p}$-value & $\mathrm{R}^{2}$ \\
\hline Cholesterol (mg/100 g) & $18.78 \pm 4.12$ & $309.50 \pm 58.31$ & $* \star \star$ & 0.09 \\
\hline Omega 3 (mg/100 g) & $0.18 \pm 0.22$ & $48.33 \pm 22.56$ & ** & 0.68 \\
\hline Aspartic acid (mg/g) & $8.39 \pm 1.40$ & $9.78 \pm 0.83$ & NS & 0.30 \\
\hline Serine $(\mathrm{mg} / \mathrm{g})$ & $3.50 \pm 0.76$ & $4.82 \pm 1.19$ & * & 0.43 \\
\hline Glutamic acid $(\mathrm{mg} / \mathrm{g})$ & $11.17 \pm 1.85$ & $12.96 \pm 1.30$ & NS & 0.27 \\
\hline Glycine $(\mathrm{mg} / \mathrm{g})$ & $2.23 \pm 0.39$ & $2.45 \pm 0.18$ & NS & 0.14 \\
\hline Histidine (mg/g) & $2.25 \pm 0.49$ & $2.79 \pm 0.18$ & * & 0.39 \\
\hline Arginine $(\mathrm{mg} / \mathrm{g})$ & $4.39 \pm 0.74$ & $5.80 \pm 0.90$ & $\star *$ & 0.47 \\
\hline Threomine $(\mathrm{mg} / \mathrm{g})$ & $2.94 \pm 0.56$ & $4.07 \pm 0.57$ & ** & 0.55 \\
\hline Alanine $(\mathrm{mg} / \mathrm{g})$ & $4.70 \pm 0.79$ & $5.01 \pm 0.40$ & NS & 0.07 \\
\hline Proline (mg/g) & $2.79 \pm 0.46$ & $3.96 \pm 0.41$ & $\star * *$ & 0.68 \\
\hline Cystine (mg/g) & $0.71 \pm 0.15$ & $0.48 \pm 0.09$ & $* * *$ & 0.50 \\
\hline Tyrosine $(\mathrm{mg} / \mathrm{g})$ & $2.52 \pm 0.53$ & $2.29 \pm 0.98$ & NS & 0.02 \\
\hline Valine $(\mathrm{mg} / \mathrm{g})$ & $5.96 \pm 0.98$ & $6.67 \pm 0.63$ & NS & 0.18 \\
\hline Methionine $(\mathrm{mg} / \mathrm{g})$ & $2.98 \pm 0.52$ & $2.41 \pm 0.24$ & * & 0.38 \\
\hline Lysine $(\mathrm{mg} / \mathrm{g})$ & $5.52 \pm 0.88$ & $7.68 \pm 1.28$ & ** & 0.54 \\
\hline Isoleucine (mg/g) & $4.31 \pm 0.69$ & $5.49 \pm 0.60$ & $\star *$ & 0.50 \\
\hline Leucine $(\mathrm{mg} / \mathrm{g})$ & $6.42 \pm 1.03$ & $8.07 \pm 1.50$ & NS & 0.33 \\
\hline Phenylalanine $(\mathrm{mg} / \mathrm{g})$ & $4.72 \pm 0.82$ & $4.44 \pm 0.33$ & NS & 0.05 \\
\hline
\end{tabular}

these hybridizations also provide the opportunity to create new and better individuals, fitted to the nowadays conditions while preserving the main characteristics of the original breed.

Ho chicken is one of the local breeds in Vietnam with a heavy weight. The body weight of adult cocks and hens were 3.78 and $2.64 \mathrm{~kg}$ on average, respectively. These results are similar to previous researches (Doan and Luu, 2006; Thuy, 2010; Moula et al., 2012a,b). According to Cuc (2010), the weights of adult Ho chickens are among the largest, with Dong Tao (3.5-4.5 $\mathrm{kg}$ ) and Choi (3.5-5 kg). Along with the large weight, the body sizes of Ho chickens such as the body length, wing length, leg length and neck length were also particularly large.

Being used in ceremonial activities, the Ho cock is also drawn on folk drawings on a special paper type and hung solemnly in the living room inside the houses in the Red River delta. Ho chickens are presented in a traditional festival organized in the early spring in Ho town, Bac Ninh province to select beautiful and representative chickens. That is one of the reasons for the farmers to often select Ho chickens with long legs, long neck and large body shape for raising. As mentioned above, the average neck lengths of the cocks and the hens were 22.33 and $19.97 \mathrm{~cm}$, respectively while the average body length of the cocks and the hens were 42.88 and $37.73 \mathrm{~cm}$, respectively. For comparison, the average neck lengths of $\mathrm{Ri}$ chickens were from 17.85 to $19.18 \mathrm{~cm}$ (cock) and from 14.66 to $15.26 \mathrm{~cm}$ (hen); the average body lengths were from $36.65 \mathrm{~cm}$ to $38.85 \mathrm{~cm}$ (cock) and from 30.54 to $32.96 \mathrm{~cm}$ (hen) (Moula et al., 2012a,b).

In the present study, the eggs production varied largely between hens. This result indicated that selection tools were not applied in the household system. The average egg production of Ho chickens is similar to the study of Doan and Luu (2006). The average egg production for one clutch was low. The low laying performances of local chicken breeds have been confirmed in many related studies (Moula et al., 2012a,b), with the Ho breed ranking among the worst in terms of eggs production by hen by year (Cuc, 2010).

When finishing each clutch, the eggs move to the hatching period. In Ho town, local people still use hens or turkeys as incubation. Many farmers used turkeys for hatching instead of Ho hens. According to the farmers, Ho hens have a heavy weight so it is difficult for them to move into the clutch, or to manipulate the eggs, which leads to a high risk of breaking the eggs. The Ho hen were considered bad broody because she do not have many feathers to maintain heat. Each year, the number of laying cycle of Ho chicken is low. The rate of eggs leading to an embryo was low. This might due to the heavy cock weights, leading to mating difficulties. The egg weight of Ho chickens was higher than those of other local chicken breeds such as Dong Tao $(48.5 \mathrm{~g})$, H'Mong (42.5 g) and Te chicken (41.62 g) (Lung et al., 2004; Thieu et al., 2004a,b). This tendency was also observed for the weight of the yolk (Lung et al., 2004; Thieu et al., 2004a,b). The Haugh unit of Ho egg is lower than the egg of H'Mong chicken, Te chicken (Lung et al., 2004; Thieu et al., 2004a,b). The amino acid contents in the yolk of Ho were lower in comparison with previous researches (My et al., 2010; Genchev, 2012). The feeds using in the different systems might affect the eggs quality.

Conclusion: The $\mathrm{Ho}$ is a chicken breed with a large dimension, a large diversity in the colors, a heavy weight, a low egg production and reproduction. A research to improve the egg production and reproduction should be 
undertaken to obtain a better economic efficiency while maintaining this genetic heritage and sustaining the biodiversity of the avian breeds in Vietnam.

\section{ACKNOWLEDGEMENTS}

This research was supported by Ministry of Education and Training and Ministry of Agriculture and Rural Development, code: 16/2012/HD-HTQTSP.

\section{REFERENCES}

AOAC, 1990. Official methods of analysis. 15th edition Edn., Arlington, VA: Association of Official Analytical Chemists.

Besbes, B., 2009. Genotype evaluation and breeding of poultry for performance under sub-optimal village conditions. World's Poult. Sci. J., 65: 260-271.

Cuc, N.T.K., 2010. Vietnamese local chicken breeds: Genetic diversity and prioritizing breeds for conservation. Georg-August Universitat, Gottingen, Germany, pp: 118.

Doan, B.H. and N.V. Luu, 2006. A survey on distribution, conformation, growth and productivity of ho chicken. J. Sci. and Dev., 4: 95-99.

Delgado, C., M. Rosegrant, H. Steinfeld, S. Ehui and C. Courbois, 1999. Livestock to 2020 the next food revolution. Discussion paper. A 2020 Vision for Food, Agriculture and the Environment 28, International Food Policy Research Institute, http://www.ifpri.org/sites/default/files/publications/ vb61.pdf, (23/12/2014).

Eaton, D., J. Windig, S. Hiemstra, M. van Veller, N. Trach, P. Hao, B. Doan and R. Hu, 2006. Indicators for livestock and crop biodiversity. Centre for Genetic Resource, the Netherlands, CGN/DLO Foundation, Wageningen, pp: 22-24.

FAO, 2012. Phenotypic characterization of animal genetic resources, fao anial production and health. Rome: Food and agriculture organization of united nations.

Genchev, A., 2012. Quality and composition of japannese eggs (coturnix japonica). Trakia J. Sci., 10: 91-101.

GSO, 2014. Statistical handbook of viet nam. General statistic office: Statistical Publishing House.

Keambou, T., Y. Manjeli, J. Tchoumboue, A. Teguia and R. Iroume, 2007. Caracterisation morphobiometrique des ressources genetiques de poules locales des hautes terres de l'ouest cameroun. Livest. Res. Rural Dev., 19.

Lan Phuong, T.N., K.D.T. Dong Xuan and I. Szalay, 2015. Traditions and local use of native vietnamese chicken breeds in sustainable rural farming. World's Poult. Sci. J., 71: 385-396.
Luan, L.D., 2014. Aspects of the vietnamese traditional culture through a proverb. Language and Life, 3: 3638.

Lung, B.D., V.T. Hung and D.L. Luong, 2004. Report keeping gene bank of dong tao chicken. In: Workshop conservation of livestock gene fund 1990-2004. National Institute of Animal Sciences, Hanoi, Vietnam, pp: 107-122.

Moula, N., N. Antoine-Moussiaux, L. Do Duc, D. Pham Kim, T. Vu Dinh, B. Dang Vu, P. Leroy and F. Farnir, 2012a. Comparaison de la qualite des œufs de deux races de poules vietnamiennes (ri et mia). In: 10eme Journeses des Sciences Veterinaires.

Moula, N., P.K. Dang, F. Farnir, V.D. Ton, D.V. Binh, P. Leroy and N. Antoine-Moussiaux, 2012b. The ri chicken breed and livelihoods in north vietnam: Characterization and prospects. J. Agric. and Rural Dev. in the Tropics and Subtropics, 112: 57-69.

My, H.N., T.N.A. Tuan and N.X. Duy, 2010. Chemical composition and amino acid content of chicken egg white. J. Sci. and Dev., 4: 693-697.

Phan Dang, T., M. Peyre, T. Vu Dinh, F. Roger, J.F. Renard and S. Desvaux, 2009. Characteristics of poultry production systems and cost-benefit analysis of mass vaccination campaign against hpai in poultry production systems in long an province, south vietnam. J. Sci. Dev., 7(English. Iss. 1).

SAS, 1989. Sas/stat. User's guide, version 6, 4th edition. Cary, NC: SAS Institute.

Thieu, P.C., VV. Su, H.V. Tieu and L.T. Thi Hong, 2004a. Report biological characteristics and production capabilities of chicken te. In: Workshop conservation of livestock gene fund 1990-2004. National Institute of Animal Science, Hanoi, Vietnam, pp: 133-144.

Thieu, P.C., V.V. Su and H.L. Son, 2004b. Conserve, selective and develop of h'mong chicken. In: Workshop conservation of livestock gene fund 1990-2004. Nationall Institure of Animal Science Hanoi, Vietnam, pp: 145-152.

Thuy, L.T., 2010. Determine the genetic variation of local breeds. Natl. Inst. of Anim. Sci., Hanoi, Vietnam, pp: 105.

Tieu, H.V., 2009. Conservation and exploitation of animal genetic resources in vietnam. Natl. Inst. of Anim. Sci. Hanoi, Vietnam, pp: 15-20.

Vang, N.D., T.C. Xuan, P.D. Tien, L.T. Nga and N.M. Hung, 1999. Possibility of mia chicken production in farming thuy phuong. Magazine Poult., 8: 35-39. 